\title{
Artículos
}

\section{VIOLENCIA DOMÉSTICA: LA RELACIÓN TERAPÉUTICA CON MUJERES SOBREVIVIENTES DE VIOLENCIA DOMÉSTICA DESDE UNA PERSPECTIVA RELACIONAL-CULTURAL'}

\author{
Merari E. Fernández Castro²
}

\section{Resumen}

La relación terapéutica con sobrevivientes de violencia doméstica es una que nos invita a reflexionar y a cuestionar los paradigmas tradicionales en la terapia. Algunos acercamientos terapéuticos, como el psicoanálisis de Freud, han promovido la importancia de la objetividad y neutralidad. Este y otros acercamientos teóricos parten de la premisa de que, los y las clientes deben llegar a sus propias conclusiones sin inmiscuir la percepción subjetiva de la o el terapeuta. La teoría relacional cultural, lejos de favorecer la neutralidad, plantea la importancia de la subjetividad, interdependencia, las relaciones con otros y la relación de terapia como agentes centrales en el proceso sanación. Este artículo tiene como objetivo discutir la teoría relacional cultural y cómo este acercamiento terapéutico puede ser útil en el trabajo con sobrevivientes de violencia doméstica.

[Descriptores: relación terapéutica, sobreviviente, violencia doméstica, teoría relacional-cultural, desconexión, conexión, autenticidad, paradoja relacional, imágenes relacionales, empatía, empatía mutua].

${ }^{1}$ Este artículo se enfoca en la violencia doméstica sufrida por mujeres por parte de sus novios, esposos o parejas consensuales del sexo opuesto. Se hará alusión a la mujer como sobreviviente de la violencia doméstica, aunque reconociendo que de igual forma mujeres y hombres en relaciones heterosexuales, homosexuales o lésbicas sobreviven la violencia doméstica. Estadísticamente las mujeres son el grupo que más sufre la violencia doméstica a nivel mundial (United Nations Development Fund for Women, 2003). Evanston, IL.

${ }^{2}$ Trabajadora social y terapeuta en Womencare Counseling Center, 


\section{Abstract}

The therapeutic relationship with domestic violence survivors invites us to reflect and to question traditional paradigms used in therapy. Some therapeutic approaches, such as Freudian psychoanalysis, promote the importance of objectivity and neutrality. This and other therapeutic approaches propose that clients should get to their own conclusions without the intromission of the subjective perception of the Therapist. The relational cultural theory, far from supporting neutrality, emphasizes the importance of subjectivity, interdependence, relationships with others and the therapeutic relationship as central agents in the healing process. This article has the objective to discuss the relational cultural theory and how its therapeutic approach could be useful in working with domestic violence survivors. [Keywords: therapeutic relationship, survivor, domestic violence, relational-cultural theory, disconnection, connection, authenticity, relational paradox, relational images, empathy, mutual empathy].

\section{El problema de la violencia doméstica como un problema relacional}

La violencia doméstica es una experiencia en la que la sobreviviente encuentra limitado su sentido de libertad personal. La capacidad de establecer relaciones consigo misma y con personas de relativa cercanía afectiva es lacerada. Su confianza en otros y su derecho a mantener relaciones de mutualidad se encuentran amenazados. A través de la historia se ha documentado y explicado el problema de la violencia doméstica como uno que tiene sus raíces en la familia de origen ya que se entiende los agresores provienen de familias en las que se ha vivido la violencia doméstica considerándose este como un problema intergeneracional (Pollak, 2002). Algunos críticos de estos postulados indican que las mismas son posturas tradicionales que culpan a la familia nuclear y al individuo de un problema que tiene sus raíces en el marco social (Websdale \& Johnson, 2008). Sin embargo, lejos de querer responsabilizar a las sobrevivientes de los problemas interpersonales y relacionales a las que se enfrentan, en este artículo se pretende explicar cómo intervenciones y marcos teóricos con un enfoque cultural y relacional recogen ambas perspectivas en función de promover el proceso de sanidad de quienes han sufrido y 
han atestiguado la violencia doméstica (Pederson, Crethar, \& Carlson, 2008).

\section{La teoría relacional - cultural}

Para comprender la aportación que puede hacer la teoría relacional cultural al trabajo con sobrevivientes de violencia doméstica, es imprescindible conocer el trasfondo e historia del desarrollo de la misma. La teoría relacional cultural despuntó al publicarse el libro Toward Psychology of Women en 1976 por la psiquiatra Jean Baker Miller (Jordan, 2010). Miller criticó el énfasis de las teorías psicológicas en catalogar como debilidades los mecanismos psicológicos que las mujeres utilizaban para sobreponerse a los problemas y reconsiderarlas como fortalezas. Miller criticó a las teorías psicológicas del desarrollo debido a su énfasis en la neutralidad y en el logro de la independencia personal como indicador de éxito. Esta propuso que el desarrollo humano se construye de acuerdo con enormes fuerzas sociales y en relación con otras y otros. Miller estableció las relaciones como un componente principal en el crecimiento personal y cuestionó la utilidad del uso del yo.

En 1978, Miller empezó a trabajar con otras tres psicólogas, quienes se dedicaron a analizar casos y a cuestionar las teorías psicodinámicas tradicionales y su falta de atención a las experiencias de las mujeres. Para el 1981, el grupo comenzó a publicar y presentar sus ideas a través de Estados Unidos.

A través de los últimos años se ha publicado una gran cantidad de libros y artículos en la que se presenta el desarrollo de la teoría relacional cultural. Miller, Carol Gilligan y sus estudiantes de escuela graduada comenzaron a reunirse para discutir sus ideas presentándolas en Harvard Medical School. Más adelante comenzaron a expandir el reconocimiento de las experiencias de las mujeres de color, lesbianas, mujeres con limitaciones físicas y de diferentes contextos económicos. Estas se dieron cuenta que aquella opresión que estaban señalando, la perpetuaban al no ser inclusivas de otros grupos fuera de mujeres blancas y de clase media alta.

Judith Jordan (2010) explica que en el 1981 se fundó el Stone Center for Developmental Studies and Services en Wellesley College con la colaboración de Irene Stiver, PhD., Judith V. Jordan, PhD., y Janet Surrey, PhD. En 1995 se creó The Jean Baker Miller Training Institute para continuar trabajando 
en el desarrollo de la teoría relacional cultural. El instituto ha preparado adiestramientos, talleres sobre neurobiología de las relaciones, madres e hijos e hijas y mentoría (Jean Baker Miller Training Institute, 2013). Existe una red de investigación que ofrece un foro anual para compartir los trabajos realizados que se inspiran en la teoría relacional- cultural. La teoría relacional no es estática sino que continúa evolucionando en la medida que se incorporan nuevas ideas. El objetivo de la teoría es la búsqueda de la equidad en las relaciones. Esta teoría puede ser de gran utilidad para trabajar con sobrevivientes de violencia doméstica debido a que trabaja los aspectos del modelaje y la experimentación del desarrollo de relaciones auténticas y de mutualidad en el contexto terapéutico.

\section{La violencia doméstica}

Mucho se ha escrito sobre las raíces sociales de la violencia doméstica y cómo la misma ha sido creada y reproducida por el patriarcado (Gelles \& Levine, 1996; Silva Bonilla, 2002; Valle Ferrer, 2007). Al analizar estos escritos, encontramos ejemplos concretos de cómo nuestras sociedades han sido cómplices de este crimen en las que miles de mujeres y niños sufren las repercusiones de este problema social. Esta perspectiva macrosocial nos ayuda a analizar las situaciones que presentan las sobrevivientes de violencia doméstica desde una postura no punitiva e individualista. Realizar observaciones en nuestras intervenciones terapéuticas con las sobrevivientes sobre como la estructura o el sistema social en el que esta interactúa les re-victimiza o cómo la respuesta de familiares y amigos podría perpetuar la violencia contra la misma, desenfocan la responsabilidad que usualmente nuestra sociedad sitúa en el individuo, sino en aquellos agentes sociales de opresión de las mujeres.

En el contexto relacional, las sobrevivientes vienen al encuentro terapéutico con dificultades producto de las experiencias traumáticas que estas han vivido en la sociedad patriarcal en las que se desenvuelven. Muchas sufren efectos postraumáticos presentando retos en el establecimiento de nuevas relaciones. Señalar a la cultura y a los diversos sistemas de opresión como estrategia de validación puede ser un componente importante en la terapia. Sin embargo, otro componente a considerar en nuestra interacción con sobrevivientes de violencia doméstica es la relación terapéutica como eje central de sanación (Walker, 2004). 
En este ámbito la teoría relacional cultural enfatiza que lo político es personal y lo personal es político (Madoo Lengermann \& Niebrugge-Brantley, 1993). Este postulado feminista comprende cómo aspectos de injerencia macrosocial como lo son las fuerzas sociales que inciden en la violencia doméstica, afectan a quienes lo sobreviven en su carácter personal. Las sobrevivientes reconocen su experiencia individual de violencia como una que también se manifiesta en ellas en el colectivo social.

Por otro lado, la relación individual con la o el terapeuta es uno de los vehículos más poderosos de sanación personal luego de una experiencia traumática. Es a través de esta relación terapéutica que existe la oportunidad de crear conexión y cercanía en donde el abuso es inaceptable y el respeto, la responsabilidad y la mutualidad son fundamentales (Kahn, 2006). Judith Herman (1997) menciona en su libro Trauma and Recovery sobre el trabajo con sobrevivientes de trauma, en el contexto de una relación en la que surgió la experiencia traumática, y es a través de una relación en la que se pueden crear los procesos de sanación individual. Teniendo en cuenta el poder de las relaciones y su capacidad para destruir y construir, la labor terapéutica es revertir las experiencias traumáticas a través de la relación terapéutica. La o el terapeuta identificará aquellas vulnerabilidades como resultado de la violencia doméstica como podrían ser la desconexión, la desconfianza, el temor, la exacerbación y la desconexión propia de las emociones (Walker, 2004).

No solo la relación con la o el terapeuta es de suma importancia, sino la relación que la sobreviviente tenga con la comunidad. La sobreviviente podrá acercarse a la resolución de la experiencia de abuso cuando la comunidad restituya y responsabilice a quienes le han causado daño emocional (Herman, 1997). Quienes han sobrevivido una experiencia traumática como la violencia doméstica, la negligencia, el maltrato infantil o la violación mencionan que dentro de esta experiencia, lo más traumático ha sido la inacción o la negación de la violencia por aquellos que conocían de la misma. En el caso de las sobrevivientes de violencia doméstica, una de las experiencias que muchas mencionan como traumática, además del acto de violencia en sí, , es cómo las responsabilizan por el mismo, y la falta de mecanismos sociales para que los agresores 
rindan cuentas por sus actos. En estas circunstancias, la brecha entre la comunidad y la sobreviviente necesita estrecharse a través de la acción comunitaria y el reconocimiento público del daño perpetrado contra la sobreviviente.

\section{Modelo feminista relacional cultural y la violencia doméstica}

La teoría relacional cultural reta algunas nociones tradicionales de la psicología en términos del yo, la autonomía, la independencia, la individualización y la competencia (Baker Miller, Jordan, Stiver, Walker, Surrey, \& Eldridge, 2004). La teoría relacional cultural lejos de ofrecer técnicas de intervención, comprende una serie de postulados filosóficos feministas. Esta propone que el establecimiento de relaciones auténticas y de conexión mutua son necesidades humanas importantes. La misma también establece que la desconexión en las relaciones es una fuente de problemas psicológicos y causante de enormes sufrimientos (Herman, 1997). Este no es un modelo del experto actuando sobre una persona o haciendo interpretaciones sobre lo que la paciente enferma necesita cambiar. Más bien es un acto colectivo (terapeuta y sobreviviente, pareja o familia) en el que se busca contrarrestar los efectos de las manifestaciones del sistema patriarcal en la vida de las personas.

La teoría relacional-cultural enfatiza que existen escalas de posiciones de autoridad en la sociedad y que muchos entran a estas relaciones, en particular mujeres y grupos minoritarios, en posición de desventaja. Los postulados de esta teoría sostienen que la validación de las experiencias de la sobreviviente, incluyendo la diferencia de poder y los factores sociales que causan su sufrimiento, son aspectos imprescindibles a señalar. La teoría y modelo relacional cultural, más que ayudar a la sobreviviente a adaptarse a circunstancias de vida opresivas, enfatiza la importancia de encontrar aliadas para examinar las formas en las que se puede resistir prácticas vergonzosas desde un frente colectivo e individual (Jordan, 2010). La o el terapeuta en este contexto establece una alianza en la que lejos de ayudar a la sobreviviente a adaptarse a las circunstancias, le motiva y promueve la resistencia a la violencia de la que es objeto. La teoría relacional cultural considera la importancia de mantener autoconsciencia sobre la diferencia de poder a la que vienen a la relación la o el terapeuta y la sobreviviente. En este reconocimiento la o el terapeuta identifica momentos en 
el que la relación ha sido utilizada para mantener control de las interpretaciones conductuales y emotivas de la sobreviviente. La sobreviviente es un ente activo y participa en la construcción de las interpretaciones de sus experiencias de vida.

La teoría y modelo relacional-cultural busca disminuir el sufrimiento de las personas causadas por la desconexión y el asilamiento a nivel individual o social para así incrementar la capacidad de establecer relaciones que promueven la sanidad personal y la justicia social. Una de las propulsoras de esta teoría, Walker (2004), manifiesta que la desconexión y el aislamiento en las relaciones ocurren en un contexto de racismo, sexismo, sexualización y estratificación junto con otras dimensiones como lo son la clase social, habilidades físicas, religión o cualquier otro aspecto que sea significativo en la cultura. Esto coincide con la experiencia de las sobrevivientes de violencia doméstica como una de desconexión y aislamiento, en muchos casos, debido a su género. El aislamiento y desconexión de su pareja es evidente y este asume capas mucho más profundas cuando la violencia doméstica se enmarca en la manifestación opresiva del racismo, clasismo y marginación.

\section{Desconexión}

La experiencia de desconexión que plantea la teoría relacional cultural se explica como la ruptura de una relación. Esto puede ocurrir cuando la persona ha sido lastimada, decepcionada o violentada. La teoría relacional cultural sostiene además que, las desconexiones en relación al otro son normativas pues también puede ocurrir cuando otros mal entienden, invalidan, excluyen o humillan a la otra persona de alguna forma. Si estas desconexiones se pueden manejar, las mismas no causarían problemas en el futuro (Jordan, 2010). Sin embargo, si la persona que ha sido lastimada no se le permite o promueve que hable de lo que le ha dolido o molestado, aprenderá a suprimir su experiencia. Ella o el aprende a esconder lo que siente y a no ser auténtica para mantenerse en relación con el o la otra. La persona comienza a sentirse desapoderada, y si esto ocurre de forma repetida, se desarrolla una situación crónica de desconexión como ocurre continuamente en las relaciones de violencia en donde la sobreviviente esconde lo que piensa por temor a represalias del agresor. Esta dinámica crea aislamiento y en ocasiones la persona puede perder contacto con sus emociones (Jordan, 2010). 
La desconexión es una experiencia muy presente en la vida de la sobreviviente de violencia doméstica debido a que ocurre una desconexión de sí misma, de sus emociones, del amor que siente por el agresor y de aquellos a los que mantiene en alta estima. Debido al control ejercido hacia la sobreviviente, la misma se ve limitada a acudir a quienes pueden ayudarle. La sobreviviente se ve limitada a mantener relaciones con personas significativas o a mantener actividades en la comunidad que le llenen de vitalidad y significado. Judith Herman (1997, p.50) recoge lo antes explicado definiendo la desconexión traumática como "la brecha en el apego hacia la familia, amistades, el amor y la comunidad".

La desconexión puede manifestarse y replicarse en la relación con la o el terapeuta. Una sobreviviente de violencia doméstica podría percibir una desconexión al interactuar con una o un terapeuta que no muestre emociones, que mantenga distancia y se reúse a compartir impresiones. La sobreviviente ha experimentado la desconexión con el agresor ya que este ha retirado su afecto a la sobreviviente como una forma de control (Walker, 1979). Las personas que han sufrido experiencias crónicas de trauma, como lo es la violencia doméstica, pueden desarrollar la capacidad de percibir estados anímicos de las personas a su alrededor, así como el de sus terapeutas, y notar cuando existe algún sentimiento negativo, de desaprobación o de juicio valorativo hacia su persona. Esta habilidad de notar la desconexión es un mecanismo de sobrevivencia pues así, la sobreviviente ha podido percibir estados de ánimos en su agresor y saber cuándo está en peligro (Bass \& Davis, 1994).

\section{Conexión}

La conexión, por otro lado, es uno de los postulados de la teoría que se explica como las relaciones caracterizadas por empatía y apoderamiento mutuo. Las personas se sienten lo suficientemente cómodas como para ser vulnerables y emocionalmente accesibles ante el otro. Jordan (2004) explica que cuando somos lastimadas o violentados en relaciones significativas, en especial cuando ocurre de forma crónica, nos sumergimos profundamente en aislamiento defensivo y tememos a la conexión.

La desconexión y la conexión pueden verse en el siguiente ejemplo: Mariela, sobreviviente de violencia doméstica, insiste en justificar a su terapeuta la razón por la que permaneció 
en la relación con el agresor a pesar de que la terapeuta entiende la razón de las mismas. La terapeuta comprende el contexto social en el que se desenvuelve la sobreviviente donde constantemente se le cuestiona por permanecer en la relación de violencia doméstica teniendo que explicar sus decisiones ante los demás. La terapeuta le preguntó a Mariela si algo de lo que ella ha dicho ha sido percibido como un cuestionamiento de su decisión de haber permanecido en la relación abusiva. La sobreviviente le comunica a la terapeuta que siempre ha tenido que explicar sus decisiones porque no la entienden y tal vez dude de que la terapeuta entienda su decisión de haber permanecido por ocho años en una relación abusiva. La terapeuta entonces le comunica a la sobreviviente cuán difícil debió haber sido haber tenido que tomar la decisión de permanecer en esta relación y ser juzgada por sus familiares; reafirmó entender las razones para esta permanecer en la relación y mencionó que puede apreciar cuán difícil fue terminar con una relación tan compleja. En este caso, la terapeuta está prestando atención a la desconexión y se dirigió a reparar la brecha existente entre ambas dirigiéndose hacia la conexión.

\section{La paradoja de la relación}

Existe una paradoja en la relación terapéutica en la que la sobreviviente desea y busca la conexión, sin embargo, a veces se aterroriza ante la misma y utiliza mecanismos de desconexión para protegerse. Este es el resultado de estar en constante conexión y desconexión en sus relaciones personales debido a la violencia emocional y física. La sobreviviente desea conectar con su pareja pero a la misma vez siente temor de acercarse por temor a ser lastimada nuevamente. Esta experiencia paradójica podría replicarse en la sesión terapéutica. Walker (2004) explica que el reto de la o el terapeuta es mantener la empatía aun cuando ambas fases paradójicas se presenten en la relación de terapia. Si el o la terapeuta retira su conexión en relación a esta paradoja, probablemente habrá un impase en la relación.

Jordan (2010) explica que es necesario que la terapeuta reconozca las razones por la que la sobreviviente ha tenido que recurrir a estos mecanismos paradójicos de desconexión y entender cómo estos le han servido para protegerse en el pasado. En ocasiones, esto se puede manifestar cuando las sobrevivientes parecen muy entusiasmadas con la terapia, sin embargo, son inconsistentes en asistir a sus citas. 
Otros mecanismos de desconexión podrían ser la ausencia de emociones o la poca información ofrecida en sesiones subsecuentes a sesiones donde ha abundado la expresión de las emociones y la información; exponer las fallas terapéuticas de la terapeuta a otros; no revelar información relevante; o hacer uso de mecanismos emotivos como el coraje o la jocosidad para mantener distancia afectiva. Estas reacciones podrían ser debido a que la presencia de la o el terapeuta es importante, pero su presencia incondicional puede que resulte sospechosa, atemorizante y cuestionable (Herman, 1997). En el caso de las sobrevivientes de violencia doméstica, las experiencias de conexión mutua han sido precedidas por abuso haciendo que la sobreviviente retire su afecto esperando que ocurra lo peor en cualquier momento.

Otros ejemplos paradójicos relacionales surgen cuando la sobreviviente no expresa lo que su necesidad a la terapeuta así como, en otras relaciones o contextos. Generalmente este comportamiento es visto como un problema de "asertividad" recayendo la explicación en una deficiencia psicológica. Este comportamiento tiene sus raíces en la autoprotección ya que surge a raíz de experiencias pasadas en el que las personas alrededor no respondieron a lo que la sobreviviente necesitaba en momentos de necesidad o vulnerabilidad; la experiencia deja a la sobreviviente lastimada y esta cuestiona cuán sabio es tornarse a otros para obtener ayuda (Jordan, 2004). Esta, es considerada como una de las reacciones traumáticas más comunes ante el abandono y la traición. Queda de la o el terapeuta explorar las motivaciones de la sobreviviente al no buscarle cuando pudo haber obtenido la ayuda necesaria. La terapeuta podría llevar a cabo acciones que demuestren que estará allí para ayudarle en momentos de vulnerabilidad.

\section{Autenticidad}

La autenticidad o capacidad de que ambas -tanto la o el terapeuta como la sobreviviente- estén completamente presentes en una relación, se considera como un eje central en el proceso de terapia. La sobreviviente no podría tener una idea de quién realmente es la o el terapeuta si no muestra quien es en relación a su cliente. Presentarse de forma auténtica, tal cual la o el terapeuta es, es uno de los factores que contribuyen al éxito de la relación profesional, siendo la relación profesional uno de los indicadores de éxito en la terapia (Horvath \& Luborsky, 1993). 
Autenticidad significa mostrar apertura a discutir lo que la o el terapeuta siente en relación a la sobreviviente. En ocasiones la autorevelación con propósito definido puede ser utilizada como un mecanismo para fortalecer la conexión en la relación terapéutica (Baker Miller, Jordan, Stiver, Walker, Surrey, \& Eldridge, 2004). Negar la experiencia afectiva o tratar de establecer fronteras rígidas, distanciaría a la sobreviviente aún más.

La o el terapeuta no necesita hablar de todo lo que siente de forma que utilice la sesión para beneficio personal. Lo importante es estar conscientes de los propios procesos emocionales de modo que puedan ser revelados, de estos beneficiar el proceso de la sobreviviente. Para muchas y muchos es un reto cuando estos procesos emocionales de la o el terapeuta son percibidos y mencionados por la sobreviviente. La reflexión relacional lleva a balancear el reconocimiento de las emociones propias ante la sobreviviente y el espacio personal de la o el terapeuta. La o el terapeuta podría mantener la información personal para sí misma de ser necesario para la protección personal y la sobreviviente. Jordan (2010) explica que presentarnos de forma auténtica en la relación terapéutica envía algunos mensajes de índole relacional a la sobreviviente. La sobreviviente puede ver su impacto en los demás brindándole un sentido de control y de importancia.

La autenticidad podría observarse en el siguiente ejemplo: Sofía, sobreviviente de violencia doméstica, describió en terapia detalles de la experiencia de abuso sexual perpetrada por su novio. El terapeuta se sintió conmovido con una combinación de rabia, coraje, decepción y tristeza al escuchar su historia. Sofía detiene su relato al observar el rostro del terapeuta y mencionó no estar segura que el terapeuta pueda tolerar escuchar el resto de la historia. El terapeuta decidió mostrarse de forma auténtica ante la sobreviviente mencionándole: "Estoy conmovido por el dolor que has tenido que pasar. Estoy aquí para escucharte y sentir contigo la complejidad de emociones que esta experiencia pudo haber causado en ti”.

\section{Imágenes relacionales}

La teoría relacional-cultural presta atención a las imágenes relaciones. Estas son imágenes internas o ideas que se han formado a través de las propias experiencias en 
el pasado y en las que se asume que las personas tendrán el mismo comportamiento en el presente o el futuro. La teoría relacional entiende que las desconexiones crónicas en la vida desarrollan imágenes relacionales negativas (Jordan, 2010). Este concepto es similar a la "transferencia" de la que habla Freud en donde el paciente transfiere sus conflictos de la niñez a la relación del analista y el paciente (Freud, 1953,1974). Sin embargo, la teoría relacional entiende que estas imágenes relacionales se replican en múltiples relaciones manteniendo a las sobrevivientes con la sensación de sentirse "estancadas en el pasado". Estas imágenes se convierten en el foco de exploración en las sesiones terapéuticas.

Al trabajar con sobrevivientes de violencia doméstica, las imágenes relacionales que podríamos encontrarnos, serían que, la sobreviviente pensara que va a ser severamente castigada si dice lo que siente. Estas imágenes provienen de la experiencia vivida con el agresor, o sus padres o madres, $\mathrm{u}$ otras personas significativas. Esta imagen relacional se convierte en un obstáculo para que esta pueda expresar lo que piensa y sienta a otros en subsiguientes relaciones. La o el terapeuta puede explorar imágenes relacionales que discrepen de dicha imagen como por ejemplo: "Aquella vez que le hablé a mi madre sobre cómo me sentía, esta me escucho y apoyó". Otra manera puede ser: "Tengo otras amigas que han estado ahí para escuchar como me siento".

En ocasiones, la o el terapeuta podría utilizar el trabajo de imágenes relacionales cuando ocurren rupturas empáticas o desconexiones en la relación terapéutica. Por ejemplo, que la sobreviviente sienta que su terapeuta no ha entendido su dolor y es malentendida. Una oportunidad para reparar la relación es que la o el terapeuta reconozca su desconexión terapéutica y valide pues la experiencia de la sobreviviente. El sentido de insignificancia, incompetencia y aislamiento de la sobreviviente puede comenzar a cambiar en esta interacción con su terapeuta (Jordan, 2010).

\section{Empatía y empatía mutua}

La empatía, un concepto mencionado frecuentemente en Trabajo Social y en los modelos de intervención terapéutica, es de particular trascendencia en este marco teórico. Mas allá 
de ser una técnica inicial para establecer la relación y ganar la confianza de la sobreviviente, se convierte en sí misma en gran parte de la esencia de la relación terapéutica. Walker (2004, p.10) citando a Jordan define empatía como "destrezas afectivas-cognoscitivas complejas que implican la habilidad de unirse a otros y otras en sus experiencias, mientras se mantiene claridad cognoscitiva sobre la fuente de la reacción emocional de la sobreviviente". Se entiende que el trabajo de sanación realmente ocurre cuando existe empatía debido a que la persona se mueve del aislamiento hacia verse a sí misma como merecedora de respeto y conexión. Varios autores (Schore, Allan en Jordan, Judith, 2010) mencionan, incluso, el efecto de la empatía en donde existe una resonancia activa en el cerebro entre terapeuta y cliente lo cual podría alterar el funcionamiento del cerebro de forma positiva.

La empatía mutua, por otro lado, nos ubica fuera de paradigmas tradicionales de la $\circ$ el trabajador social 0 terapeuta como el vehículo de empatía, sino que se reconoce el efecto que las experiencias de la sobreviviente tienen en su terapeuta. La o el terapeuta no solo siente activamente cómo la sobreviviente le ha tocado y cambiado, sino que lo demuestra en la relación. La o el terapeuta demuestra en su interacción que la historia y experiencia de la sobreviviente realmente son importantes. Walker (2004) explica que dada las experiencias traumáticas de las sobrevivientes, fallar en mencionar el impacto de la sobreviviente en su terapeuta puede evocar sentimientos de vergüenza e ineptitud, tal vez similares a las experiencias opresivas que estas han vivido con otras personas en posiciones de poder. Cuando se ha estado en desconexión crónica, como lo son las relaciones de violencia doméstica, la falta de respuesta empática de la pareja, la falta de afecto, la pérdida de esperanza de que en algún momento se recibirá respeto consistente, y la desmoralización son la orden del día. Cuando la o el terapeuta se presenta a la sesión completamente en relación empática, la sobreviviente podrá descartar las expectativas de que las relaciones fallarán subsecuentemente.

\section{La teoría relacional-cultural: Una teoría clínica para el Trabajo Social}

El Trabajo Social se caracteriza por su fuerte vínculo a los valores de la justicia social y al trabajo con poblaciones 
marginadas (National Association of Social Workers, 2008). El mismo, no solo enfatiza en la mirada al individuo más allá de su situación particular, sino a su realidad social y al contexto en que se desenvuelve (Zastrow \& Kirst-Ashman, 2001).

Las y los trabajadores sociales que han asumido el rol de terapeutas podrían enfrentarse al reto de utilizar marcos de intervención y teorías psicológicas como el psicoanálisis de Freud, la psicología del yo o la teoría objeto-relacional, para mencionar algunas. Estas teorías y acercamientos terapéuticos se encuentran muy lejos de enfatizar en el contexto social más allá de las relaciones de los individuos consigo mismos, sus madres, padres o personas significativas. Una de las críticas de las exponentes de la teoría relacional cultural al psicoanálisis es su énfasis en el mundo intrapsíquico de las personas, en el establecimiento de fronteras para protegerse de estímulos externos o del peligroso mundo exterior (Jordan, 2010). Freud también planteaba que las relaciones son secundarias en la obtención de la satisfacción, lo cual se distancia de la teoría relacional cultural y su énfasis en el establecimiento de las relaciones humanas (Freud, 1953,1974). Christina Robb (2006) plantea que de acuerdo con Freud, Piaget, Erikson, Kholberg y otros psicólogos que trabajaron en teorías del desarrollo, la mayoría de las mujeres no desarrollaron un fuerte ego para defenderse de otros egos, no se proponen ser independientes, ganar y usar el racionamiento abstracto. Esto nos lleva al planteamiento de la importancia de evaluar, cuestionar las teorías de manera que sean cónsonas con los valores de la igualdad entre los géneros (Zastrow \& Kirst-Ashman, 2001).

El reto en el rol terapéutico de mantener no solo una mirada clínica-individual, sino en el contexto y el establecimiento de relaciones humanas no autoritarias, es cónsono con las prácticas y valores del Trabajo Social (Colegio de Profesionales del Trabajo Social de Puerto Rico, 2013). Enfocarse tan solo en el uso de alguna de estas perspectiva psicológicas, lejos de ayudar a promover cambios sociales, depositan las responsabilidades de cambio en la sobreviviente de violencia doméstica (Hawley, 2001). Las y los individuos pueden hacer cambios de índole individual y resolver sus problemas particulares, sin embargo, la mirada a las relaciones, lo social y cómo nuestra relación afecta a nuestras y nuestros clientes es imperativo. 
En el caso de la violencia doméstica, lo cual ha sido señalado como un problema social, mirar solo a la sobreviviente utilizando teorías individualistas exacerba y perpetúa el problema (Silva Bonilla, 1985). Nos convertimos entonces en aquello que la sociedad capitalista y el estado necesita: adaptar a los individuos a su ambiente de forma que no se cuestionen la organización social en la que viven. La teoría relacional-cultural, sin embargo, hace mención del contexto, del sexismo, del prejuicio social y el racismo y propone mencionar y señalar estos aspectos en la relación terapéutica con la sobreviviente (Jordan, 2010). La teoría relacional-cultural asume una postura social. EI uso de la teoría relacional-cultural cuestiona las interacciones autoritarias y patriarcales a las que las mujeres han sido objeto a través de la historia. Utilizar este perspectiva terapéutica como trabajadoras y trabajadores sociales en nuestro rol como terapeutas cuestiona en si mismo la presente organización de las relaciones sociales. La relación terapéutica es utilizada para reorganizar la manera en que hemos aprendido a relacionarnos (generalmente relaciones autoritarias y desiguales) hacia una que promueva la conexión y la autenticidad siendo estos el eje y el comienzo del proceso de sanación.

Este acercamiento teórico y filosófico puede incluirse en el currículo de Trabajo Social como uno de los marcos teóricos a los que se adhiere la práctica terapéutica con personas que han sufrido experiencias traumáticas o han sufrido discriminación social. La inclusión de este marco teórico enriquecerá la diversidad de teorías presentadas a las y los estudiantes y proveerá a la necesidad de utilizar teorías que respondan a la realidad de las mujeres y poblaciones en desventaja social. Esta teoría no solo se diferencia de marcos teóricos psicológicos tradicionales, sino de los marcos teóricos sociológicos feministas que (Payne, 2005), por otro lado, no ofrecen herramientas terapéuticas concretas para trabajar con sobrevivientes que han sufrido violencia doméstica y otras experiencias traumáticas.

Al proponer que esta sea una teoría a incorporarse al currículo de Trabajo Social, enfrentamos varios dilemas. Uno de estos es la resistencia de profesionales de ayuda como el Trabajo Social y la psicología a acercamientos identificados como feministas (Bakers, 1997, Abramovitz en Flynn Saulnier, 2008). Por otro lado, se ha documentado la discriminación hacia 
la mujer dentro de la profesión de Trabajo Social reflejando las opiniones prejuiciadas hacia la mujer por parte de la sociedad en un contexto más amplio (Dattalo, 2006 \& Krane, 1990 en Flynn Saulnier, 2008) lo que podría limitar la preferencia en el uso de esta teoría entre los estudiantes y egresados.

Otro de los dilemas al incorporar esta teoría al currículo de Trabajo Social, es que es una que ha surgido y se ha desarrollado en el contexto de la cultura estadounidense. La misma podría utilizarse, adaptarse y desarrollarse desde una perspectiva latinoamericana como parte del proceso de aprendizaje. La teoría enfatiza considerablemente en las relaciones como fuente de transformación personal y social, lo cual es compatible con la importancia del establecimiento de relaciones en el contexto latinoamericano.

\section{Conclusión}

La teoría relacional cultural nos brinda un acercamiento único y diferente en la relación con sobrevivientes de violencia doméstica. La misma promueve el apoyo y la solidaridad con aquellas que han sufrido experiencias traumáticas. Mas allá de enfatizar en técnicas particulares, la teoría enfatiza una perspectiva filosófica feminista al trabajar con sobrevivientes de trauma. No es hasta que promovamos la autenticidad a través de la relación con nuestras y nuestros clientes que podremos ver profundas transformaciones. Muchas de las sobrevivientes de violencia doméstica han tenido que esconder quienes son por temor a represalias por parte de sus parejas violentas. Nosotras y nosotros podemos ser un vehículo importante para el proceso de transformación personal abriendo espacios para que la sobreviviente muestre realmente quién es sin temor. Khan (2006) explica que el proceso terapéutico nos enseña que el conocimiento de lo que es cierto y de quiénes somos no deben sacrificarse por amor, sino que son cruciales; la vulnerabilidad facilita la cercanía y confianza, no la humillación o el peligro. 


\section{REFERENCIAS}

Baker's Dozen. (1997). Feminist student voices. En Judith Worell \& Norine G. Johnson. Shaping the future of feminist psychology: Education, research and practice. (pp. 227-248) Washington, DC: American Psychological Association.

Baker Miller, Jean, Jordan, Judith V., Stiver, Irene P., Walker, Maureen, Surrey, Janet L., Eldrige, Natalie S. (2004). Therapist's authenticity. En Judith Jordan, Maureen Walker, \& Linda M. Hartling (Eds.), The complexity of connection. (pp. 64-89) New York, NY: The Guildford Press.

Bass, Ellen, \& Davis, Laura. (1994). The courage to heal: A guide for women survivors of child sexual abuse. ( $3^{\text {rd }}$ ed.) Santa Cruz, CA: Harper Perennial.

Colegio de Profesionales del Trabajo Social de Puerto Rico. (2013). Código de ética profesional. Recuperado de: http://www. cptspr.org/pdf/codigo_etica.pdf

Flynn Saulnier, Christine. (2008). Feminist theories. En Nick Coady \& Peter Lehman. Theoretical perspectives for direct social work practice: A generalist-eclectic approach. (2nded., pp. 343-366) Springer Publishing Company. New York.

Freud, Sigmund. (1953-1974). The Standard edition of the complete psychological works of Sigmund Freud. (24 vols.) James Strachey (Trad.). London: Hogarth.

Gelles, Richard, \& Levine, Ann. (1996). Introducción a la sociología: Con aplicaciones a los países de habla hispana. (5th ed.) México, D.F.: Mc Graw Hill/Interamericana Editores, S. A. DE C.V.

Hawley, Nancy P. (2001). La salud mental. En Nirvana González, Maribel Nieves, Laura Colon-Martínez, Rosario Cardich, Elena Brauchy \& Myriam Hernández-Jennings, Nuestros cuerpos, nuestras vidas. Siete Cuentos Trans. NY: Editorial. New York

Herman, Judith. (1997). Trauma and Recovery: The aftermath of violence-from domestic abuse to political terror. New York, NY: Basic Books.

Horvath, Adam O., \& Luborsky, Lester. (1993). The Role of the therapeutic alliance in psychotherapy. Journal of consulting and clinical psychology, 61 (4), 561-573.

Jean Baker Miller Training Institute. (2013). The Development of relational cultural therapy. Recuperado de: http://www.jbmti. org/Our-Work/the-development-of-relational-cultural-theory

Jordan, Judith. (2004). Relational awareness. En Judith Jordan, Maureen Walker\& Linda M. Hartling (Eds.), The complexity of connection: writings from the Stone Center's Jean Baker Miller Training Institute. (pp. 47-63) New York, NY: The Guildford Press. 
Jordan, Judith. (2010). Relational-cultural therapy. Washington, DC: American Psychological Association.

Khan, Laurie. (2006) The understanding and treatment of betrayal trauma as traumatic experience of love. Journal of trauma practice, 5 (3), 57-71.

Madoo Lengermann, Patricia, \& Niebrugge-Brantley, Jill. (1993) Teoría feminista contemporánea. En George Ritzer, (Ed.) Teoría sociológica contemporánea. (pp. 353-409) Madrid, España. Mc Graw Hill.

National Association of Social Workers. (2008) Código de ética: Revisado por la Asamblea de Delegados de NASW de 2008. Recuperado de: http://www.socialworkers.org/ pubs/code/ code.asp?c $=\mathrm{sp}$

Payne, Malcolm. (2005) Feminist Perspectives. Modern Social Work Theory. ( $3^{\text {rd }}$ ed., pp. 251-268) Chicago, IL. Lyceum Books Inc.

Pederson, Paul, Crethar, Hugh C., Carlson, Jon et al., (2008) Inclusive cultural empathy: Making relationships central in counseling and psychotherapy. Washington, DC: American Psychological Association.

Pollack, Robert A. (2002) An intergenerational model of domestic violence. [Monografía]. Recuperado de: www.nber.org/papers/ w9099.pdf

Silva Bonilla, Ruth. (1985) ¡Ay!, ¡Ay! Amor: No me quieras tanto (EI marco social de la violencia contra las mujeres en la vida conyugal). En Ruth Silva Bonilla, Mayra Muñoz Vázquez \& Nilsa Torres Hernández (Eds.), La violencia nuestra de cada día: Manifestaciones de la violencia contra las mujeres (pp. 1-60). San Juan, Puerto Rico: Centro de Investigaciones Sociales, Universidad de Puerto Rico, Recinto de Rio Piedras.

United Nations Development Fund for Women. (2003) Not a minute more: Ending violence against women. Recuperado de: http://www.unifem.org/attachments/products/300_book_ eng_02.pdf

Valle Ferrer, Diana. (2007) Validating coping strategies and empowering Latino battered women in Puerto Rico. En Albert R. Roberts (Ed.) Battered women and their families: Intervention strategies and treatment programs. ( $3^{\text {rd }}$ ed., pp. 563-590) New York, NY: Springer Publishing Company

Walker, Leonore. (1979). The battered woman. New York: Harper \& Row.

Walker, Maureen. (2004) How relationships heal. En Walker, Maureen \& Rosen, Wendy B.(Eds.), How connections heal: Stories from relational cultural therapy (pp.3-21). New York, NY: The Guildford Press. 
Websdale, Neil, \& Johnson, Byron. (2008) Reducing women battering: The role of structural approaches. En Natalie Sokoloff (Ed.), Domestic violence at the margins: Readings of race, class, gender and culture (pp. 389-415). Piscataway, NJ: Rutgers University Press.

Zastrow, Charles, \& Kirst-Ashman, Karen K. (2001). Understanding Human Behavior and the Social Environment (5ta ed). Belmont, CA: Brooks Cole. 